\title{
INFLUÊNCIA DA TEMPERATURA DE SECAGEM SOBRE AS PROPRIEDADES FÍSICAS DOS GRÃOS DE SOJA
}

Fernando Mendes Botelho ${ }^{1}$, Suian José Granella², Sílvia de Carvalho Campos Botelho ${ }^{3}$ Taise Raquel Bechlin Garcia $^{4}$

\section{RESUMO}

Objetivou-se com o presente trabalho avaliar o efeito da temperatura de secagem sobre algumas propriedades físicas de grãos de soja. Para avaliar o efeito da temperatura, amostras de grãos de soja com teor inicial de água de 0,244 (b.s.) foram secadas numa estufa com circulação forçada de ar nas temperaturas de $40,50,60,70$ e $80{ }^{\circ} \mathrm{C}$ até o teor final de água de 0,136 (b.s.), sendo então determinadas as propriedades físicas: ângulo de repouso, massa específica aparente, massa específica unitária, massa de mil grãos, cor e condutividade elétrica da solução dos exsudatos dos grãos. Notouse que, à exceção da porosidade, a temperatura do ar de secagem influenciou significativamente as propriedades físicas de grãos de soja, proporcionando aumento do ângulo de repouso e da condutividade elétrica da solução dos exsudatos. As massas específicas aparente e unitária, massa de mil grãos e a cor característica dos grãos de soja diminuíram com o aumento da temperatura do ar empregado na secagem. Concluiu-se que o aumento da temperatura do ar de secagem diminuiu a qualidade dos grãos de soja analisados.

Palavras-chave: Glycine max, características físicas, qualidade

\begin{abstract}
INFLUENCE OF DRYING TEMPERATURE ON THE PHYSICAL PROPERTIES OF SOYBEAN GRAINS

The objective of this study was to evaluate the effect of drying temperature on physical properties of soybeans. To evaluate the effect of temperature, soybean samples with an initial moisture content of 0.244 (db) were dried in an standard hot air oven at temperatures of 40,50,60,70 and $80{ }^{\circ} \mathrm{C}$ until reaching the final moisture content of $0.136(\mathrm{db})$, followed by determining the physical properties: angle of repose, bulk density, real density, one thousand grain weight, color and electrical conductivity of the solution of the soybean exudates. It was noted that the drying temperature significantly influenced the physical properties of soybeans, resulting in increased angle of repose and electrical conductivity of the exudate solutions. The bulk and real densities, one thousand grain weight and the characteristic color of soybeans decreased with increasing drying temperature. It was concluded that as the drying temperature increase there was a decrease in quality of the grains analyzed.
\end{abstract}

Keywords: Glycine max, physical characteristics, quality

\footnotetext{
Recebido para publicação em 10/02/2015. Aprovado em 11/05/2015.

1 - Eng ${ }^{\circ}$ Agrícola, Professor Adjunto de Engenharia Agrícola da UFMT/Sinop-MT, fernando_eaa@yahoo.com.br

2 - Eng ${ }^{\circ}$ Agrícola, Aluno, UFMT/Sinop-MT, suiangranella@hotmail.com

3 - Eng ${ }^{\mathrm{a}}$ Agrônoma, Dr ${ }^{\mathrm{a}}$ em Eng. Agrícola, Pesquisadora, Embrapa Agrossilvipastoril, silvia.campos@embrapa.br

4 - Enga Agrícola, Ex-aluna, UFMT/Sinop-MT, tayse_raquel@hotmail.com
}

\section{REVENG}




\section{INTRODUÇÃO}

A secagem é umas das principais operações pós-colheita, pois, além de possibilitar uma armazenagem de forma segura, também pode promover alterações nas características físicas e mudanças qualitativas indesejáveis como a descoloração, oxidação, trinca ou quebra dos grãos.

O estudo das propriedades físicas dos produtos agrícolas e dos fatores que as influenciam é de grande importância para a avaliação e tomada de decisões nas operações de colheita e póscolheita de grãos e na otimização dos processos agroindustriais (RESENDE et al., 2005).

Uma das mudanças físicas mais importantes que ocorrem nos produtos agrícolas durante a secagem é a redução do seu volume. A perda de água causa mudanças na forma e, normalmente, proporciona decréscimo nas dimensões características dos grãos, fenômeno usualmente conhecido como contração volumétrica, sendo uma das principais causas das alterações das principais propriedades físicas dos produtos agrícolas. No entanto, o teor de água é relatado como o parâmetro que mais influencia as propriedades físicas dos produtos agrícolas. Assim, inúmeros autores têm investigado a influência de uma série de fatores sobre as variações das propriedades físicas para diversos produtos agrícolas durante a secagem, principalmente em função do teor de água como: feijão fradinho (DI LANARO et al. 2011), sementes de gergelim (DARVISHI, 2012), grão de bico (EISSA et al., 2010), amendoim (ARAÚJO et al., 2014), soja (SHIRKOLE et al., 2011; WANDKAR et al., 2012) pinhão-manso (SIQUEIRA et al., 2012) e fava (LORESTANI; GHARI, 2012).

Por ser o fator de maior influência, a quase totalidade dos trabalhos disponíveis na literatura que avaliam a variação das propriedades físicas ao longo do processo de secagem, apenas a dependência com o teor de água é investigada, sendo proporcionalmente poucos os que estudam outros fatores que podem interferir nas características físicas e na qualidade dos produtos agrícolas durante seu processamento, como a temperatura, por exemplo.

De acordo com a temperatura de secagem empregada, algumas características físicas e fisiológicas dos grãos podem ser alteradas. Faroni et al. (2006) verificaram que o aumento da temperatura do ar de secagem diminuiu a qualidade fisiológica de grãos de feijão ao longo do armazenamento. Siqueira et al. (2012) verificaram que a temperatura do ar de secagem alterou a circularidade e a esfericidade de grãos de pinhãomanso.

Diante do apresentado, e assumindo que a temperatura do ar empregada no processo de secagem pode alterar algumas características físicas dos produtos agrícolas, objetivou-se com o presente trabalho avaliar o efeito da temperatura do ar de secagem sobre as propriedades físicas (ângulo de repouso, massas específicas aparente e unitária, massa de mil grãos, porosidade, cor e condutividade elétrica da solução dos exsudatos) dos grãos de soja.

\section{MATERIAL E MÉTODOS}

O presente estudo foi realizado no Laboratório de Energia e Pós-colheita pertencente ao Instituto de Ciências Agrárias e Ambientais da Universidade Federal de Mato Grosso, campus de Sinop (MT) e na Emprapa Agrossilvipastoril, localizada em Sinop (MT).

Foram utilizados grãos de soja da safra 2013/2014, cedidos por uma unidade armazenadora de grãos localizada no município de Sinop (MT). Os grãos foram coletados no momento da descarga do caminhão, sendo levados para o laboratório para que fosse realizada a limpeza e a retirada de grãos avariados, como os quebrados, ardidos, mofados e verdes. Os grãos coletados possuíam, em média, o teor inicial de água de 0,244 (b.s.) e foram mantidos em câmara, tipo $\mathrm{BOD}$, a $3{ }^{\circ} \mathrm{C}$ até que fosse realizada a secagem.

O teor de água do produto foi determinado pelo método gravimétrico utilizando uma estufa com circulação forçada de ar a $105 \pm 1{ }^{\circ} \mathrm{C}$, durante $24 \mathrm{~h}$, com três repetições de $30 \mathrm{~g}$ (BRASIL, 2009).

Os grãos de soja foram submetidos à secagem em uma estufa com circulação forçada de ar nas temperaturas de $40,50,60,70$ e $80{ }^{\circ} \mathrm{C}$. Essas temperaturas são normalmente empregadas na secagem de grãos nos diferentes secadores de altas temperaturas. Para cada temperatura, utilizaramse duas amostras (repetições) com massa de 1000 $\mathrm{g}$, dispostas em bandejas de chapa galvanizada e perfurada $(\varnothing=2,5 \mathrm{~mm})$, com dimensões médias de $320 \times 260 \times 50 \mathrm{~mm}$. A redução do teor de água ao longo da secagem foi acompanhada pela perda de massa, utilizando-se uma balança analítica com resolução de $0,01 \mathrm{~g}$. As amostras foram secadas até atingirem o teor de água de 0,136 (b.s.). Após 
atingir esse teor, a secagem foi interrompida e as amostras encaminhadas para determinação das propriedades físicas avaliadas neste trabalho.

Para determinação do ângulo de repouso, foi utilizado um dispositivo feito de fibra de média densidade (MDF), sendo uma de suas laterais feita de vidro para possibilitar a visualização dos grãos. O dispositivo possui um registro de contenção, que, quando aberto, possibilita o escoamento do produto, a formação e a medida do seu talude. Foram feitas cinco repetições para cada temperatura do ar de secagem.

A massa específica aparente $\left(\rho_{\mathrm{ap}}\right)$ foi mensurada utilizando-se um recipiente cuja relação entre o diâmetro e a altura é igual a um, e cujo volume é de $1 \mathrm{~L}$. Um funil com registro de descarga acoplado a uma haste permitiu que o recipiente fosse preenchido completamente sempre nas mesmas condições. Para medição da massa de grãos contida no recipiente, foi usada uma balança analítica com resolução de $0,01 \mathrm{~g}$, sendo feitas cinco repetições para cada temperatura do ar de secagem.

Para determinar a massa específica unitária $\left(\rho_{u}\right), 100$ grãos de soja foram aleatoriamente selecionados nas amostras secadas em cada temperatura testada. Obtidas as amostras, a massa e as dimensões características principais (maior dimensão, dimensão intermediária e menor dimensão característica), como ilustrado na Figura 1, dos 100 grãos, foram determinadas utilizando-se uma balança analítica com resolução de $0,01 \mathrm{~g}$ e, um paquímetro digital, com resolução de $0,01 \mathrm{~mm}$, respectivamente.

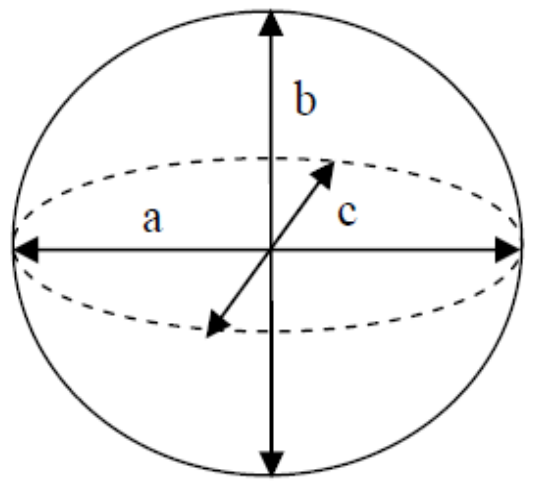

Figura 1. Desenho esquemático de um grão de soja, em que: "a", "b" e "c" são respectivamente a maior, a intermediária e a menor dimensão característica do produto.
A massa específica unitária foi determinada pela Equação 1 (MOHSENIN, 1986).

$\rho_{\mathrm{u}}=\frac{\mathrm{m}_{\mathrm{g}}}{\mathrm{V}_{\mathrm{g}}}$

em que,

$\rho_{\mathrm{u}}=$ massa específica unitária $\left(\mathrm{kg} \mathrm{m}^{-3}\right)$;

$\mathrm{m}_{\mathrm{g}}=$ massa do grão $(\mathrm{kg}) \mathrm{e}$;

$\mathrm{V}_{\mathrm{g}}^{\mathrm{g}}=$ volume do grão $\left(\mathrm{m}^{3}\right)$.

Para o cálculo do volume $\left(\mathrm{V}_{\mathrm{g}}\right)$, os grãos de soja foram considerados como esferoides triaxiais escalenos e este índice determinado pela Equação 2.

$\mathrm{V}_{\mathrm{g}}=\frac{\pi}{6}(\mathrm{a} \mathrm{bc})$

em que,

$\mathrm{V}_{\mathrm{g}}=$ volume dos grãos, $\mathrm{m}^{3}$;

$\mathrm{a} \stackrel{\mathrm{g}}{=}$ maior dimensão característica dos grãos de soja $(\mathrm{m})$;

$\mathrm{b}=$ dimensão característica intermediária dos grãos de soja $(\mathrm{m}) \mathrm{e}$

$\mathrm{c}=$ menor dimensão característica dos grãos de soja $(\mathrm{m})$.

A porosidade da massa dos grãos de soja foi determinada indiretamente de acordo com a Equação 3 (MOHSENIN, 1986).

$\varepsilon=100\left[1-\frac{\rho_{\text {ap }}}{\rho_{\mathrm{u}}}\right]$

em que,

$\varepsilon=$ porosidade $(\%)$;

$\rho_{\mathrm{ap}}=$ massa específica aparente $\left(\mathrm{kg} \mathrm{m}^{-3}\right) \mathrm{e}$

$\rho_{\mathrm{u}}=$ massa específica unitária $\left(\mathrm{kg} \mathrm{m}^{-3}\right)$.

Para a determinação da massa de mil grãos, mil grãos de soja foram secados separadamente numa bandeja, sendo sua massa acompanhada por meio de uma balança analítica com resolução de $0,01 \mathrm{~g}$.

A determinação da cor dos grãos de soja foi realizada com auxílio de um colorímetro tristímulo, com leitura direta de refletância das coordenadas $L^{*}$ (luminosidade), $a^{*}$ (tonalidades vermelha ou verde) e $b^{*}$ (tonalidades amarela ou azul) em três repetições, empregando a escala Hunter-Labe

\section{REVENG}


utilizando o iluminante $10^{\circ} / \mathrm{D} 60$.

A alteração na integridade celular, devido à secagem e aos danos naturais ocorridos nas membranas dos grãos, foi avaliada pelo extravasamento de solutos celulares. A determinação consistiu em obter uma amostra de 50 grãos inteiros de soja que, após pesada, foi imersa em $75 \mathrm{~mL}$ de água deionizada e colocada em câmara do tipo BOD com temperatura ajustada à $25{ }^{\circ} \mathrm{C}$ durante $24 \mathrm{~h}$. A condutividade elétrica da água de embebição foi medida por meio de um condutivímetro devidamente calibrado com solução padrão. O resultado da leitura deste índice foi obtido pela relação da condutividade lida pela massa da amostra (50 grãos), expressa em $\mu \mathrm{S} \mathrm{cm}^{-1}$ $\mathrm{g}^{-1}$, em quatro repetições

Os dados experimentais foram submetidos à análise de variância seguida de regressão linear, utilizando-se o programa Sisvar $^{\circledR}$, sendo selecionado o modelo matemático mais adequado para expressar a relação entre as propriedades físicas e a temperatura do ar de secagem. O grau de ajuste do modelo foi avaliado pela magnitude do coeficiente de determinação e pela significância dos coeficientes dos modelos ajustados pelo teste $t$, avaliado pela magnitude do $p$-valor, ao nível de $10 \%$ de probabilidade.

\section{RESULTADOS E DISCUSSÃO}

$\mathrm{Na}$ Figura 2 estão apresentados os valores observados e estimados do ângulo de repouso dos grãos de soja em função da temperatura do ar de secagem.

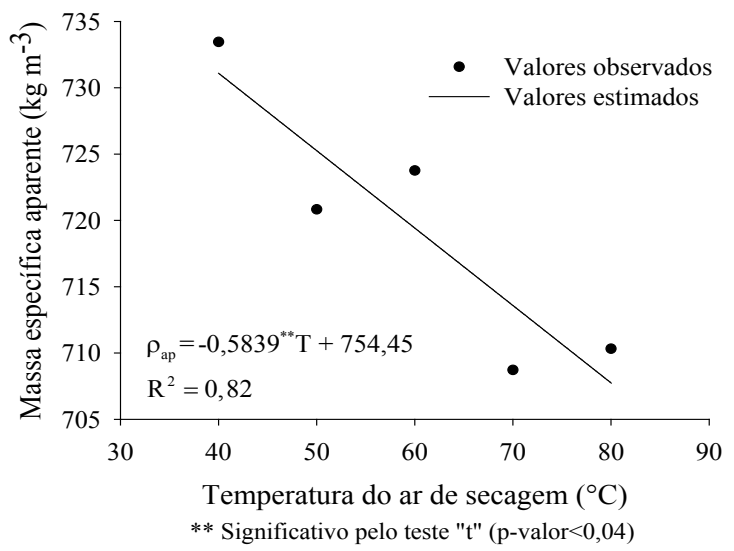

(A)

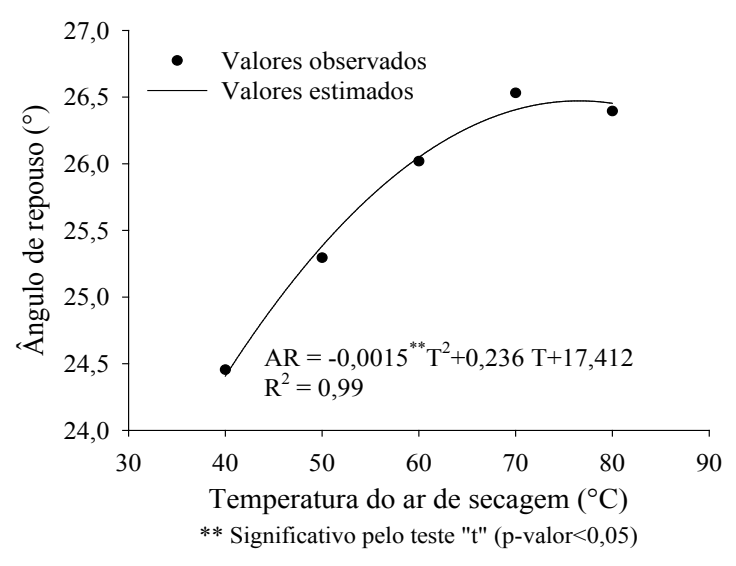

Figura 2. Valores observados e estimados do ângulo de repouso de grãos de soja secados em diferentes temperaturas do ar.

Observa-se que o valor de ângulo de repouso dos grãos de soja aumentou em função da elevação da temperatura do ar de secagem, apresentando uma tendência quadrática, variando de 24,4 a $26,4^{\circ}$, e um valor máximo correspondendo a $26,5^{\circ}$ para as temperaturas variando de 40 a 80 ${ }^{\circ} \mathrm{C}$. Valores semelhantes de ângulo de repouso foram encontrados por Tavakoli et al. (2008) e Razavi et al. (2009) para grãos de soja e de canola, respectivamente, considerando-se teores de água semelhantes aos utilizados neste trabalho. A dependência do ângulo de repouso com a temperatura do ar de secagem pode ser explicada de forma significativa por meio de uma equação polinomial de segundo grau, que apresentou bom ajuste aos dados experimentais $\left(R^{2}=0,99\right)$.

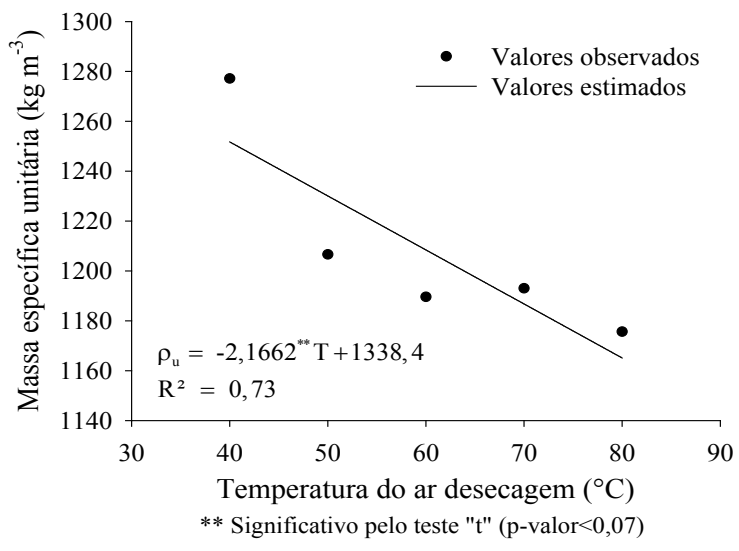

(B)

Figura 3. Valores observados e estimados da massa específica aparente (A) e massa específica unitária (B) de grãos de soja secados em diferentes temperaturas do ar. 
$\mathrm{Na}$ Figura 3 estão apresentados os dados observados e estimados das massas específicas aparente e unitária dos grãos de soja em função da temperatura de secagem.

Observa-se que tanto a massa específica aparente quanto a massa específica unitária dos grãos da soja reduziram linearmente com a elevação da temperatura, variando de 733,4 a 710,3 $\mathrm{kg} \mathrm{m}^{-3}$ e de 1277 a $1175 \mathrm{~kg} \mathrm{~m}^{-3}$, respectivamente, para a faixa de temperatura de secagem de 40 a 80 ${ }^{\circ} \mathrm{C}$. O modelo linear descreveu significativamente a redução da massa específica aparente e unitária com o aumento da temperatura do ar de secagem, apresentando os coeficientes de determinação de 0,82 e 0,73 , respectivamente.

A massa específica é uma característica física frequentemente utilizada para se avaliar a qualidade de uma massa de grãos, de modo que, normalmente, quanto maior a sua magnitude, melhor a qualidade do produto, sendo frequentemente utilizada na comercialização de alguns produtos como trigo e cevado, por exemplo. De fato, Carvalho e Nakagawa (2000) relatam que as sementes com maior massa específica são aquelas que possuem os embriões mais bem formados e com maior quantidade de tecidos de reserva (endosperma e perisperma, por exemplo). Diante disto, verificouse que o aumento da temperatura do ar de secagem influenciou negativamente a qualidade final dos grãos de soja.

Diferentemente do observado para a massa específica aparente e unitária, a porosidade da massa de grãos de soja não foi afetada pela temperatura do ar de secagem (Figura 4).

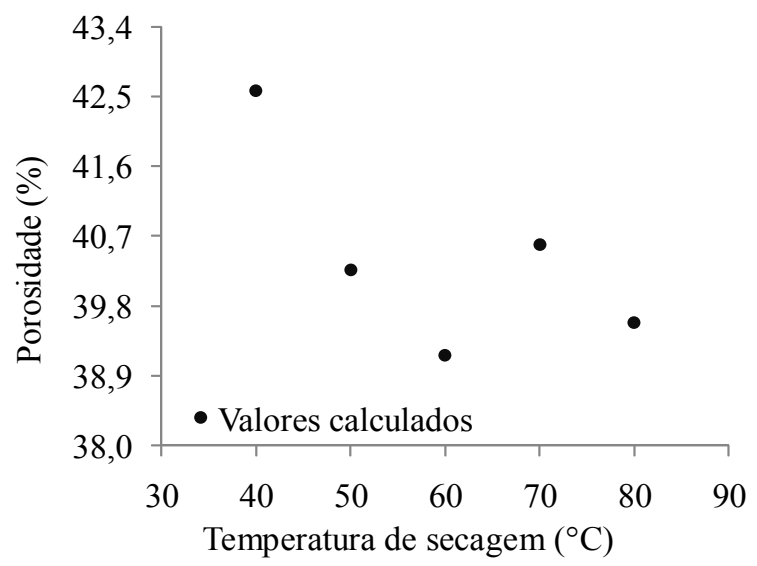

Figura 4. Valores calculados da porosidade dos grãos de soja em função da temperatura do ar de secagem.
Os valores de porosidade dos grãos de soja variaram de 42,6 a $39,2 \%$ para a faixa de temperatura estudada $\left(40-80^{\circ} \mathrm{C}\right)$ apresentando um valor médio de 40,4\%. Apesar de não apresentar dependência com a temperatura do ar de secagem, os valores da porosidade encontrados neste trabalho estão condizentes com os relatados por Wandkar et al. (2012) que observaram magnitudes entre 39,65 e $42,38 \%$ para uma faixa de teor de água de 7,37 a $15,80 \%$ (b.s.).

$\mathrm{Na}$ Figura 5 estão apresentados os valores observados e estimados da massa de mil grãos de soja em função das diferentes temperaturas de secagem.

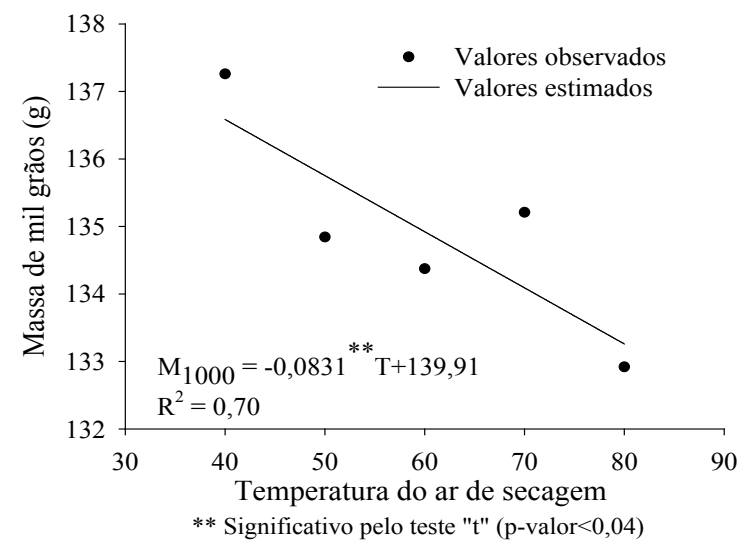

Figura 5. Dados observados e estimados da massa de mil grãos de soja em função da temperatura do ar de secagem.

Analisando os resultados, verifica-se que, com o aumento da temperatura de secagem de 40 para 80 ${ }^{\circ} \mathrm{C}$, a massa de mil grãos reduziu significativamente de 137,2 g para $132,9 \mathrm{~g}$, sendo que o modelo linear descreveu de forma satisfatória a dependência entre as variáveis. Pelo modelo ajustado, verifica-se que a massa de mil grãos variou 0,0832 g para cada grau de temperatura do ar de secagem alterado.

A massa de mil grãos é também um índice qualitativo. Assim, esse resultado ratifica àqueles observados para a massa específica em relação à temperatura, ou seja, o aumento da temperatura teve consequências diretas sobre a qualidade da massa de grãos. Resultados semelhantes também foram observados por Oliveira et al. (2010), que verificaram que o aumento da temperatura do ar de secagem de 25 para $100^{\circ} \mathrm{C}$ propiciou reduções

\section{REVENG}


significativas na massa de mil grãos (40,79 a 37,83 g) de aveia branca e na sua qualidade.

$\mathrm{Na}$ Figura 6 estão apresentados os valores observados e estimados das coordenadas $L^{*}, a^{*}$ e $b^{*}$, referentes à avaliação da cor, em função da temperatura do ar de secagem.

Pode-se observar, pela Figura 6, que a coordenada $L^{*}$ não foi influenciada pela temperatura de secagem, de modo que o valor médio observado para este índice foi de 55,48, para a faixa de temperatura estudada $\left(40\right.$ a $\left.80^{\circ} \mathrm{C}\right)$. Este índice indica a quantidade de luz perceptível ao olho humano dentro de uma mesma tonalidade, ou seja, se a cor é mais clara ou mais escura e varia do branco ao preto (0-100). Assim, notase que não houve tendência ao branqueamento (ou escurecimento) dos grãos de soja quando submetidos a diferentes temperaturas de secagem.
Diferentemente da coordenada $L^{*}$, houve redução das coordenadas $a^{*} \mathrm{e} b^{*}$. A coordenada $\mathrm{a}^{*}$ (variação do verde para o vermelho) variou de 6,2 a 5,4 e a coordenada $b^{*}$ (variação do azul para o amarelo) variou de 16,7 a 15,5, entre os valores de temperatura de 40 a $80^{\circ} \mathrm{C}$. Isso significa que, com o aumento da temperatura do ar de secagem, os grãos de soja perderam sua cor característica inicial, reduzindo seu aspecto qualitativo. Resultados semelhantes foram observados por Coradi et al. (2008), estudando a influência da temperatura do ar de secagem na cor dos grãos de café, em que observaram que o aumento da temperatura do ar de secagem de 40 para $60{ }^{\circ} \mathrm{C}$ proporcionou a perda da cor verde.

Os modelos polinomiais linear e quadrático descreveram significativamente a dependência dos índices de cor $a^{*} \mathrm{e} b^{*}$, respectivamente, em função

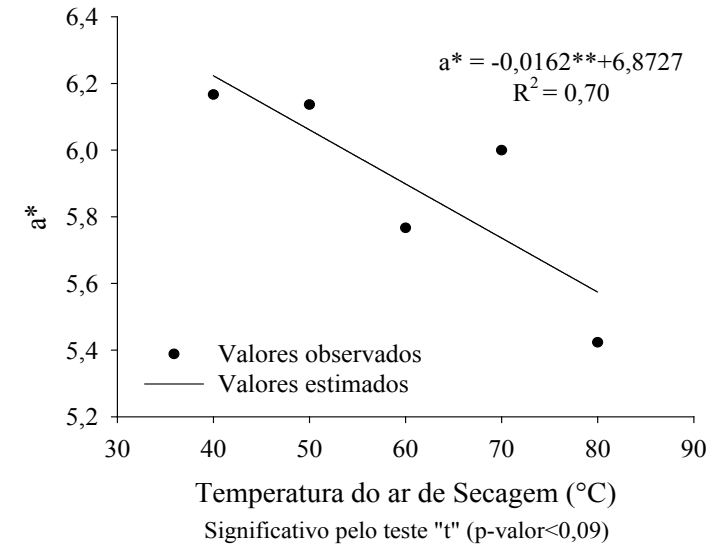

(A)

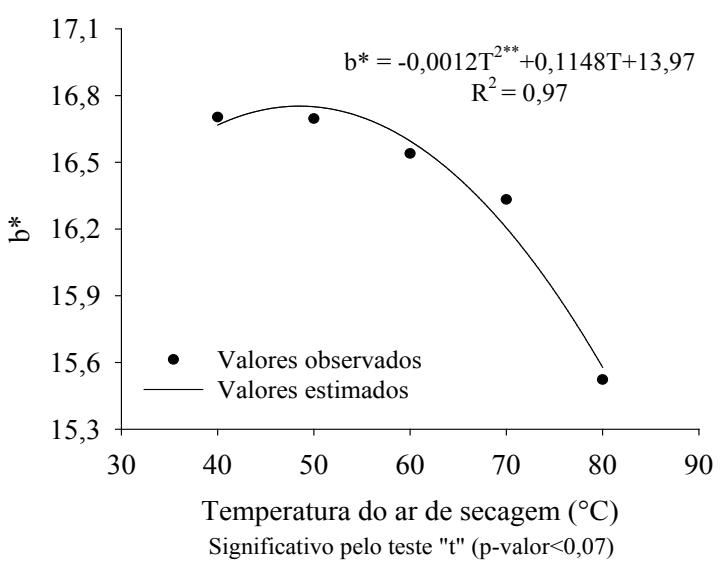

(B)

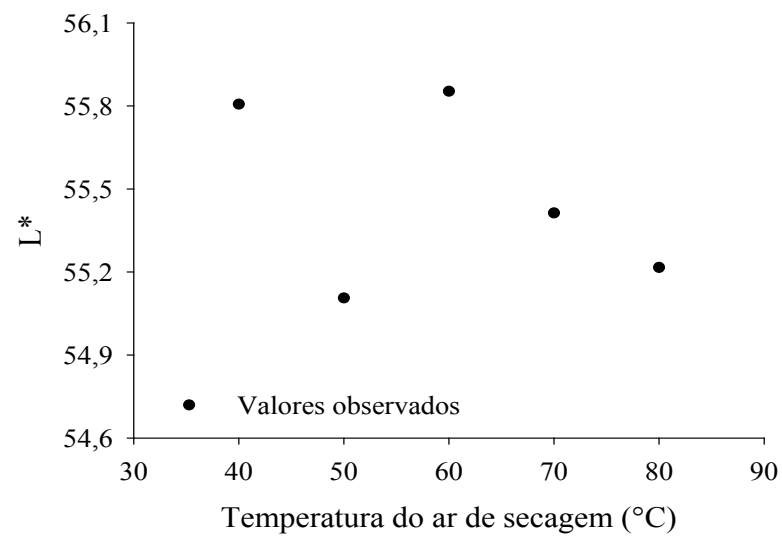

(C)

Figura 6. Dependência das coordenadas CIE $a^{*}(\mathrm{~A}), b^{*}(\mathrm{~B})$ e $L^{*}(\mathrm{C})$ dos grãos de soja em função da temperatura do ar de secagem. 
da temperatura do ar de secagem. Os coeficientes de determinação para as coordenadas $a^{*}$ e $b^{*}$ foram, respectivamente, 0,61 e 0,97.

A variação da condutividade elétrica da solução dos exsudatos dos grãos de soja em função do teor de água está apresentada na Figura 7.

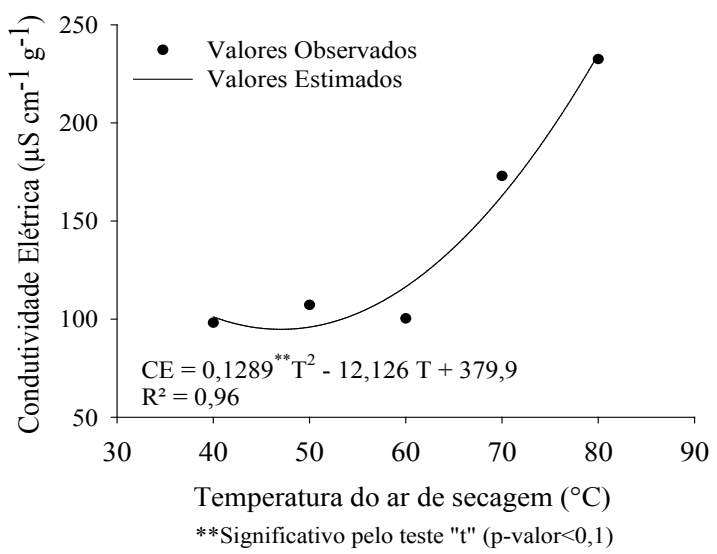

Figura 7. Valores observados e estimados da condutividade elétrica do exsudato de grãos de soja secados em diferentes temperaturas do ar de secagem.

A condutividade elétrica da solução dos exsudatos dos grãos de soja variou de 98,2 a 232,5 $\mu \mathrm{S} \mathrm{cm} \mathrm{cm}^{-1} \mathrm{~g}^{-1}$ para a faixa de temperatura do ar de secagem de 40 a $80^{\circ} \mathrm{C}$. O aumento da condutividade elétrica da solução dos exsudatos de grãos e sementes, normalmente é devido ao rompimento das membranas celulares desses produtos. Diante disso, conclui-se que houve uma perda qualitativa com o aumento da temperatura, intensificada para temperaturas maiores que $60{ }^{\circ} \mathrm{C}$. Estes resultados estão de acordo com os obtidos por Ullmann et al. (2010), para sementes de pinhão-manso, e Resende et al. (2005), em sementes de feijão na faixa de temperatura de 30 a $60^{\circ} \mathrm{C}$. Segundo Ullmann et al. (2010), temperaturas do ar de secagem acima de $60{ }^{\circ} \mathrm{C}$ proporcionaram remoção de água do interior do produto com maior intensidade em um secador experimental, causando microfissuras em nível celular.

O modelo quadrático descreveu significativamente a dependência da condutividade elétrica da solução dos exsudatos de grãos de soja em função da temperatura do ar de secagem, apresentando coeficiente de determinação de 0,96.

\section{CONCLUSÕES}

- Com exceção da porosidade, a temperatura de secagem altera significativamente as propriedades físicas analisadas, proporcionando o aumento do ângulo de repouso e da condutividade elétrica da solução dos exsudatos e a redução da massa específica aparente e unitária, da massa de mil grãos e da cor;

- O aumento da temperatura do ar de secagem de 40 para $80{ }^{\circ} \mathrm{C}$ proporciona redução da qualidade final dos grãos de soja.

\section{REFERÊNCIAS BIBLIOGRÁFICAS}

ARAÚJO, W.D.; GONELI, A.L.D.; SOUZA, C.M.A.; GONÇALVES A.A.; VILHASANTI H.C.B. Propriedades físicas do amendoim durante a secagem. Revista Brasileira de Engenharia Agrícola e Ambiental. v.18, n.3, p.279-286, 2014.

BRASIL, Ministério da Agricultura e Reforma Agrária. Secretaria Nacional de Defesa Agropecuária. Regras para análises de sementes. Brasília, 2009, 399p.

CARVALHO, N.M.; NAKAGAWA, J. Sementes: Ciência, Tecnologia e Produção. 4. ed. Jaboticabal: FUNEP, 588p. 2000.

CORADI, P.C., BORÉM, F.M., OLIVEIRA, J.A. Qualidade do café natural após diferentes tipos de secagem e armazenamento. Revista Brasileira de Engenharia Agrícola e Ambiental, v.12 (2), p.181-188, 2008.

DARVISHI, H. Moisture-Dependent Physical and Mechanical Properties of White Sesame Seed. American-Eurasian Journal Agricultural \& Environmental Science, v.12 (2): p.198-203, 2012.

DI LANARO, N.; BANJAY, L.G.; QUEIROZ, V.M.P.; PINTO, R.C.S.; LEITÃO, I.G.A.; LESSIO, B.C.; AUGUSTO, P.E.D. Determinação de propriedades físicas do feijão fradinho. Revista 
Brasileira de Produtos Agroindustriais, v.13, n.1, p.27-35, 2011

EISSA, A.H.A.; MOHAMED, M.A.; MOUSTAFA, H.; ABDUL, R.O.A. Moisture dependent physical and mechanical properties of chickpea seeds International Journal Agricultural \& Biological Engineering, v.3 (4), p.80-93. 2010.

FARONI, L.R.A.; CORDEIRO, I.C.; ALENCAR, E.R.; ROZADO, A.F.; ALVES, W.M. Influência do conteúdo de umidade de colheita e temperatura de secagem na qualidade do feijão. Revista Brasileira de Engenharia Agrícola e Ambiental v.10 (1), p.148-154, 2006.

KIBAR H.; ÖZTÜRK, T. Physical and mechanical properties of soybean. International Agrophysics, 2008, 239-244p.

LORESTANI, A.N., GHARI M. Mass Modeling of Fava bean (Vicia faba L.) with Some Physical Characteristics. Scientia Horticulturae. v.133 (6), p.6-9, 2012.

MOHSENIN, N.N. Physical properties of plant and animal materials. New York: Gordon and Breach Publishers, 1986.

OLIVEIRA, L.C.; GUTKOSKI, L.G.; ELIAS, M.C.; MAZZUTTI, S.; AOSANI, E.; ROCHA, J.C. Efeito da temperatura de secagem na qualidade de grãos de aveia branca. Ciências Agrotecnicas, Lavras, MG, v.34 (2), p.313-319, 2010.

RAZAVI, S.M.A.; YEGANEHZAD, S.; SADEGHI, A. Moisture Dependent Physical Properties of Canola Seeds. International Journal of Engineering Science and Technology, v.11, p.309-322. 2009.
RESENDE, O.; CORRÊA, P.C.; GONELI, A.L.D.; CECON, P.R. Forma, tamanho e contração volumétrica do feijão (Phaseolus vulgaris L.) durante a secagem. Revista Brasileira de Produtos Agroindustriais, v.7 (1), p.15-24, 2005.

RIBEIRO, D.M.; CORRÊA, P.C.; RODRIGUES, D.H.; GONELI, A.L.D. Análise da variação das propriedades físicas dos grãos de soja durante o processo de secagem. Ciência e Tecnologia de Alimentos, Campinas, SP, v.25 (3), p.611-617, 2005.

SHIRKOLE, S.S.; KENGHE, R.N.; NIMKAR P.M. Moisture Dependent Physical Properties of Soybean. International Journal of Engineering Science and Technology, v.3 (5), 2011.

SIQUEIRA, V.C.; RESENDE, O.; CHAVES, T.H.; SOARES, A.L. Forma e tamanho dos frutos de pinhão-manso durante a secagem em cinco condições de ar. Revista Brasileira de Engenharia Agrícola e Ambiental v.16 (8), p.864-870, 2012.

TAVAKOLI H., RAJABIPOUR A., MOHTASEBI S.S. Moisture-Dependent Some Engineering Properties of Soybean Grains. Agricultural Engineering International, v.11, 2009.

ULLMANN, R; RESENDE, O; SALES, J.F.; CHAVES, T.H. Qualidade das sementes de pinhão manso submetidas à secagem artificial. Revista Ciência Agronômica, v.41 (3), p.442-447, 2010.

WANDKAR, S.V.; UKEY, P.D; PAWAR, D.A. Determination of physical properties of soybean at different moisture levels. Agricultural Engineering International: CIGR Journal, v.14 (2), p.138-142, 2012. 